\title{
Supporting Information Stabilization of the Amorphous Structure of Spray-dried Drug Nanoparticles
}

Esther Amstad ${ }^{1,2^{*}}$, Frans Spaepen ${ }^{1}$, David A. Weitz ${ }^{1,3}$

${ }^{1}$ School of Engineering and Applied Sciences, Harvard University, Massachusetts 02138, USA

${ }^{2}$ Institute of Materials, Ecole Polytechnique Fédérale de Lausanne (EPFL),

Switzerland

${ }^{3}$ Department of Physics, Harvard University, Massachusetts 02138, USA

The microfluidic nebulator

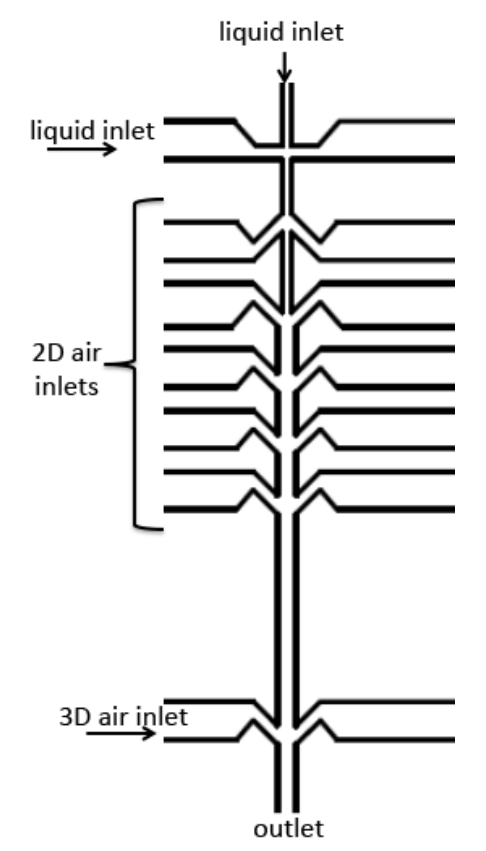

Figure S1: Schematic illustration of the junctions of the microfluidic nebulator.

The microfluidic nebulator contains two inlets for liquids and six pairs of inlets for air. The last air inlet is a three dimensional junction where the $80 \mu \mathrm{m}$ wide and 100 $\mu \mathrm{m}$ tall main channel opens up into a $300 \mu \mathrm{m}$ tall channel. We inject the liquid using 
volume controlled syringe pumps. We use a pressure regulator to control the air flux and apply the same pressure to all the air inlets.

\section{Calculations of the saturation concentration of the amorphous phase}

We calculate the saturation concentration of the amorphous phase, $c_{a, s a t}$, at room temperature using the regular solution model by equating the chemical potential of the amorphous phase in solution with that of the pure amorphous phase: $\mu_{a}^{0}+\varepsilon(1-$ $\left.x_{a, \text { equ }}\right)^{2}+R T \ln \left(x_{a, \text { equ }}\right)=\mu_{a}^{0}$, as shown in Figure $\mathrm{S} 2$. To determine $\varepsilon$, we compute $\Delta \mu$ for the crystal in equilibrium with the melt, $\mu_{c}^{0}-\mu_{a}^{0}=\varepsilon\left(1-x_{c, s a t}\right)^{2}+$ $R T \ln \left(x_{c, s a t}\right)=-\frac{\Delta H_{m} \Delta T}{T_{m}} 1$, as shown in Figure S2. The molar saturation concentration of the crystal phase of fenofibrate, $x_{c, s a t}$, in ethanol at $T=T_{m}-\Delta T=20^{\circ} \mathrm{C}$ is 0.08 , and its melting point $T_{m}$ is $80^{\circ} \mathrm{C}$. Using differential scanning calorimetry (DSC), we determine the heat of melting of fenofibrate to be $\Delta H_{m}=28.88 \mathrm{~kJ} / \mathrm{mol}$. With these values, we obtain $\varepsilon=6.7 \mathrm{~kJ} / \mathrm{mol}^{1}$ and therefore $x_{a, e q u}=0.105$ and $c_{a, e q u}=1.8 \mathrm{~mol} / \mathrm{l}$; this is 13 times higher than the equilibrium concentration of the crystal.

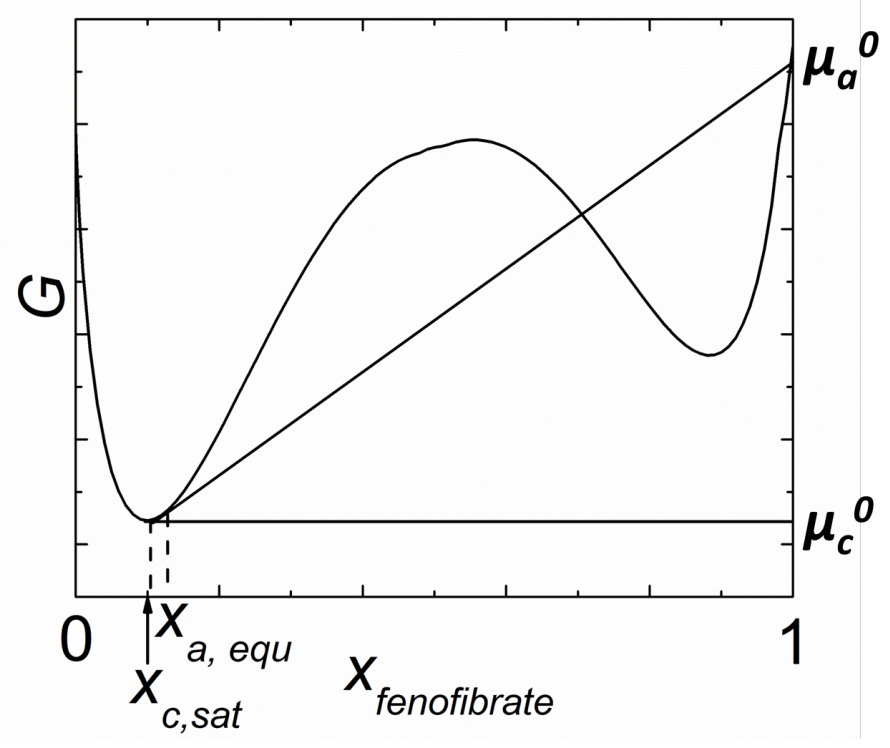

Figure S2: An example of the Gibbs free energy, $G$, as a function of the solute concentration, $x$. We use the Gibbs free energy to calculate the equilibrium concentration of the amorphous phase, $x_{a, e q u}$. 


\section{Reference}

1. Amstad, E.; Gopinadhan, M.; Holtze, C.; Osuji, C. O.; Brenner, M. P.; Spaepen, F.; Weitz, D. A., NANOPARTICLES Production of amorphous nanoparticles by supersonic spray-drying with a microfluidic nebulator. Science 2015, 349 (6251), 956-960. 